\title{
Confocal Laser Scanning Microscopic Evaluation of Sealer Penetration in Root Canals of Teeth with the butterfly and Non-butterfly Effect: An In vitro Study
}

\author{
Abraham Sathish $^{1}$, Karad Rohini Ramesh ${ }^{2 \star}$, N. Jain Ruchika ${ }^{2}$, D. Vaswani Sneha ${ }^{2}$, B. Najan Harshal ${ }^{2}$, R. Lalwani Rashi ${ }^{2}$ \\ ${ }^{1}$ Department of Conservative Dentistry and Endodontics, S.M.B.T. Dental College and Hospital and Post Graduate Research \\ Centre, Sangamner, Maharashtra, India; ${ }^{2}$ Department of Conservative Dentistry and Endodontics, S.M.B.T. Dental College and \\ Hospital and Post Graduate Research Centre, Sangamner, Maharashtra, India
}

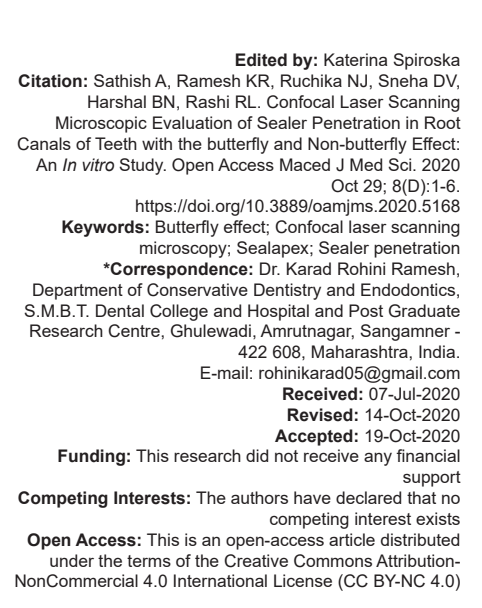

\begin{abstract}
AIM: The study aimed to investigate the penetration depth of calcium hydroxide-based root canal sealer into buccolingual and mesiodistal aspects of roots with and without the butterfly effect at coronal and middle root sections. METHODS AND MATERIALS: Twenty single-rooted maxillary premolars were decoronated at the cementoename junction and viewed under a light microscope and grouped as Group 1 - butterfly (B) and Group 2 - non-butterfly according to the presence or absence of the effect. Canals were prepared till working length followed with copious irrigation. Canals were finally rinsed with $5 \mathrm{ml}$ of $17 \%$ ethylenediaminetetraacetic acid solution and activated using EndoActivator followed by obturation using gutta-percha (warm vertical compaction technique) with Sealapex sealer To provide fluorescence for confocal laser scanning microscopy (CLSM), the Sealapex was mixed with rhodamine $B$ dye. Root sectioning yielded coronal and middle sections. CLSM was used to assess the penetration of the sealer. STATISTICAL ANALYSIS: Shapiro-Wilk test, unpaired "t-test."

RESULTS: Teeth with the butterfly effect had greater mean penetration buccolingually $(905.2 \mu \mathrm{m})$ than mesiodistally $(182.1 \mu \mathrm{m} ; \mathrm{p}<0.001)$. Coronal sections had greater penetration $(517.4 \mu \mathrm{m})$ compared with the middle $(354.6 \mu \mathrm{m})$.

CONCLUSION: Sealapex sealer exhibited maximum tubular penetration in teeth with butterfly effect in buccolingua
\end{abstract} direction at the coronal third level.

\section{Introduction}

Three-dimensional obturation of the root canal system is the final objective of non-surgical root canal therapy [1]. The currently accepted method of obturation employs a solid or semisolid core such as gutta-percha and a root canal sealer. Gutta-percha has no adhesive properties to dentin irrespective of the obturation techniques employed [2]. A root canal sealer is essential to enhance the seal during compaction and to penetrate small, normally inaccessible areas, that is, the dentinal tubules [3]. According to Orstavik, sealers play an important role in sealing the root canal system with entombment of remaining microorganisms and filling of inaccessible areas of prepared canals [4].

The effectiveness of a root canal sealer is improved by reducing the volume of sealer used, ensuring successful adaptation, and penetration of the sealer through root dentin [5]. Penetration and adaptation depend on many factors including the patency and density of the dentinal tubules. Someteethexhibitanoptical phenomenon known as the "Butterfly Effect" [6]. According to Vasiliadis et al., in 1983, dentinal tubular sclerosis differs within the mesiodistal and buccolingual directions, noting a typical butterfly shape in transverse sections of the roots [7]. Root sections with the consequence are reported to possess a lower density of dentinal tubules mesiodistally, like the wings of the butterfly. This effect has been observed in teeth from all age groups and at all levels of the roots [8]. Roots with the effect have greater penetration of sealers and mineral trioxide aggregate (MTA) buccolingually [9]. This is thought to enhance entombment of bacteria, which could lead to improved treatment outcomes [9], [10].

Calcium hydroxide-containing sealers have been in use for two main reasons - first, for stimulation of the periapical tissues to maintain health or promote healing and second for its antimicrobial effects [11]. Confocal laser scanning microscopy (CLSM) provides information on sealer penetration and distribution within the dentinal tubules using fluorescent rhodamine dye markers mixed with sealers [12].

The purpose of this in vitro study was to evaluate the penetration depth of calcium hydroxide based root 
canal sealer into buccolingual and mesiodistal aspects of roots with and without the butterfly effect at coronal and middle root sections. The null hypothesis was that there was no significant difference in sealer penetration in teeth with and without the butterfly effect.

\section{Materials and Methods}

\section{Sample Selection}

Twenty single-rooted human maxillary premolars extracted for orthodontic and periodontal reasons were included. Samples exhibiting any visible root caries, fractures, cracks, and signs of defects were excluded from the study. Selected teeth were cleansed of extraneous debris and calculus using an ultrasonic scaler. After cleansing, the specimen was rinsed under running tap water and stored in $2 \%$ thymol solution until use at $37^{\circ} \mathrm{C}$.

The sample size was calculated using $\mathrm{G}$ power 3.1.9.2 software; with confidence interval set at $95 \%$, the probability of alpha error set at $5 \%$, power of the study set at $80 \%$. The sample size was calculated to be a total of 20; divided into two groups of 10 samples each.

\section{Sample preparation}

Teeth were decoronated at the cementoenamel junction with a diamond disc (Taboom DD001 4AHP, China) under constant water irrigation. Roots were viewed under a light microscope (Olympus $\mathrm{CH} 2 \mathrm{Oi}$ ) at $\times 10$ and coded "B" butterfly or "NB" non-butterfly according to the presence or absence of the effect.

The working length was determined by subtracting $1 \mathrm{~mm}$ from the length of a size $10 \mathrm{~K}$-file (Dentsply Maillefer, Switzerland) until it reached the apical foramen. Canal orifices were flared with X-Gates files (Dentsply Tulsa Dental, Tulsa, OK, USA) and instrumentation was performed using the crown-down technique with ProTaper Next (Dentsply Maillefer, Ballaigues, Switzerland) rotary nickeltitanium instruments. The canals were prepared following sequence from X1 (size 17, 0.04 taper), X2 (size 25, 0.06 taper) to apical size X3 (size 30, 0.07 taper), till the working length. Between each instrument, the canals were irrigated with $2 \mathrm{~mL}$ of $3 \%$ sodium hypochlorite $(\mathrm{NaOCl})$ (Prime Dental Products Private Limited, Thane, India) solution. Apical patency was maintained bypassing \#15 K-file through the apical foramen between files. Then, $3 \% \mathrm{NaOCl}$ at $37^{\circ} \mathrm{C}$ was activated/delivered with Endoactivator (Dentsply Tulsa Dental Specialties, Tulsa, OK). A flush of $2 \mathrm{~mL}$ $17 \%$ ethylenediaminetetraacetic acid (EDTA) (MAARC ENDO-L, Palghar, Mumbai, Maharashtra, India) was applied for $3 \mathrm{~min}$ to eliminate the smear layer. A final rinse was performed using $5 \mathrm{~mL}$ of $0.9 \%$ saline to remove any remaining irrigating solution and the canals were dried with paper points.

All specimens were obturated with gutta-percha coated with Sealapex (Sybron Endo, Orange, CA) sealer. The sealer was mixed as per the manufacturer's recommendation. To allow analysis under the CLSM, the sealer was fluorescently labeled by adding rhodamine B (Sigma-Aldrich, St. Louis, MO, USA) at a $1: 100$ ratio by weight. All root canals were smeared with the rhodamine $B$ labeled sealer using a single ProTaper Next X3 GP cone placed to the entire working length as the master cone. The canals were obturated with a warm vertical compaction technique using Denjoy iFill (DENJOY DENTAL CO., LTD F4, CHANGSHA, CHINA). The coronal opening was sealed with a temporary filling material and the specimens were stored at $37^{\circ} \mathrm{C}, 100 \%$ relative humidity for 2 weeks to allow complete setting of the sealers.

\section{Sectioning and image analysis}

Roots were sectioned using a water-cooled slow speed diamond disc at distances 8 and $11 \mathrm{~mm}$ from the apex to yield coronal and middle sections of the roots. The maximum absorption of the rhodamine $B$ dye is $540 \mathrm{~nm}$ and the maximum emission is $625 \mathrm{~nm}$. All specimens were mounted onto glass slides and root sections were first viewed using confocal laser scanning microscope (Zeiss LSM 510, Axioplan 200, Carl Zeiss Ltd., Jena, Germany) and bird's eye view images (x10) were taken. A total of 200 images were captured corresponding to 100 apical and 100 middle root sections.

A superimposed grid was used to standardize direction records (Figure $1 \mathrm{a}$ and $\mathrm{b}$ ).

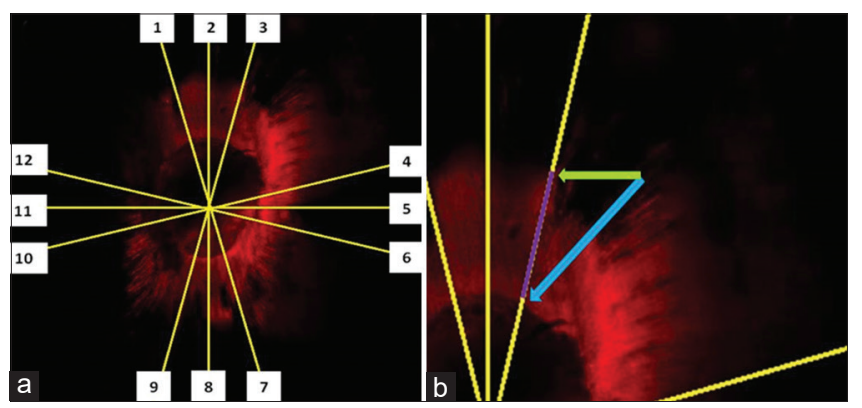

Figure 1: (a) Confocal image $(\times 10)$ of a root section showing assessment grid. Numbers correspond to: 1-3 (buccal), 4-6 (mesial), 7-9 (lingual), and10-12 (distal). (b) Measuring tool used to draw a line between the dentine-sealer interface (blue arrow) and the outermost intense red point along the gridline (green arrow) representing sealer penetration

The depth of penetration $(\mu \mathrm{m})$ was measured at 12 points using the measuring tool in ImageJ (National Institute of Health, Bethesda, MD, USA). Mean sealer penetration scores were calculated for each direction (buccolingual and mesiodistal) at two root levels (coronal and middle). 
All CLSM images were assessed by an examiner and were further assessed by two qualified endodontists. Observers viewed the images on a computer after receiving written instructions and familiarization. All three assessors were unaware which root section type was under consideration.

Statistical analysis was performed using Statistical Package for the Social Sciences version 21 for Windows (Armonk, NY: IBM Corp). Descriptive statistics including mean and standard deviation and inferential statistics were calculated. Shapiro-Wilk test showed a normal distribution of data. Unpaired "t-test" was used to compare between the butterfly and non- butterfly effect group at the coronal and middle third, respectively. For all statistical tests, $p<0.05$ has been considered statistically significant.

\section{Results}

Representative confocal images $(\times 10)$ of sealer penetration are shown in Figures 2 and 3 and the findings are presented in Tables 1 and 2. The quantitative results are depicted in Figures 4 and 5.

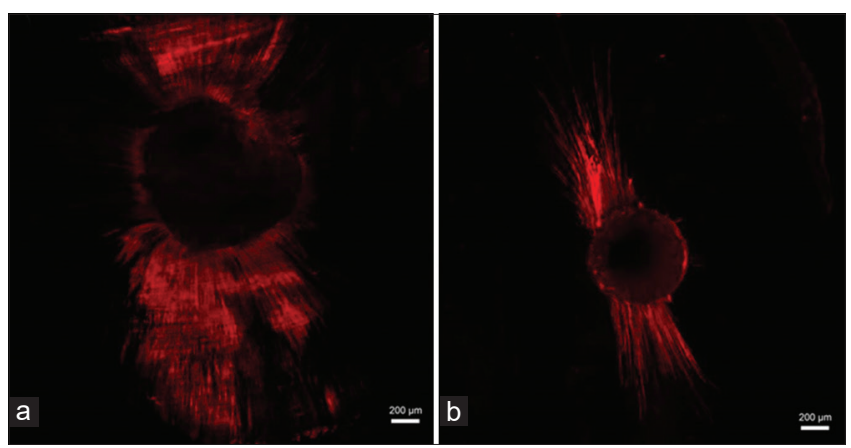

Figure 2: ( $a$ and b) Representative confocal laser scanning microscopy images $(\times 10)$ showing side-by-side comparison of coronal (a) and middle (b) penetration of Sealapex sealer in root with the butterfly effect

Greater buccolingual penetration (905.2 $\mu \mathrm{m})$ relative to mesiodistal $(182.1 \mu \mathrm{m})$ was seen in teeth with the butterfly effect ( $p<0.001$; unpaired "t-test") (Figure $2 \mathrm{a}$ and $\mathrm{b}$ and Table 1 ).

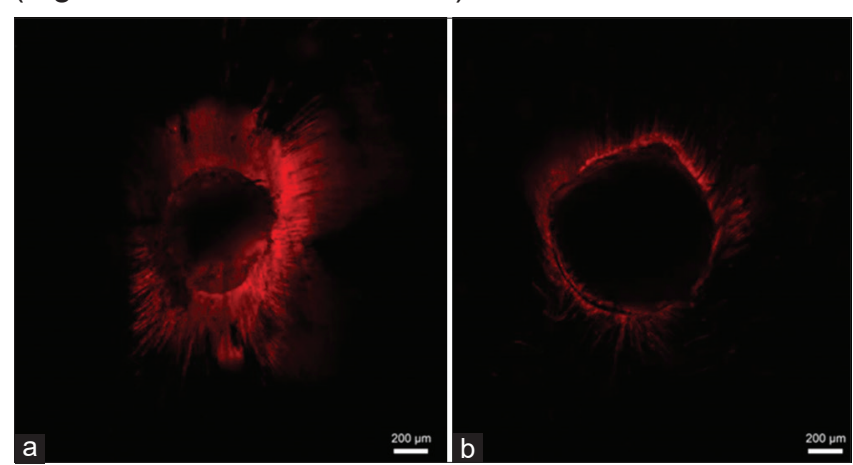

Figure 3: (a and b) Representative confocal laser scanning microscopy images $(\times 10)$ showing side-by-side comparison of coronal (a) and middle (b) penetration of Sealapex sealer in root without the butterfly effect
Table 1: Descriptive statistics of Confocal Laser Scanning Microscopic evaluation of depth of sealer penetration (in $\mu \mathrm{m}$ ) in root canals of teeth with the butterfly (Group 1) and Nonbutterfly effect (Group 2) at coronal third and middle third respectively

\begin{tabular}{lllll}
\hline Group 1 (butterfly effect) & & & & \\
\hline Coronal third & Mean & SD & Minimum & Maximum \\
\hline Buccolingual & 905.2 & 115.94 & 731.0 & 1097.0 \\
Mesiodistal & 182.1 & 28.28 & 115.0 & 219.0 \\
\hline Middle third & Mean & SD & Minimum & Maximum \\
\hline Buccolingual & 823.2 & 40.31 & 736.0 & 868.0 \\
Mesiodistal & 55.2 & 7.11 & 47.0 & 68.0 \\
\hline Group 2 (non-butterfly effect) & & & \\
\hline Coronal third & Mean & SD & Minimum & Maximum \\
\hline Buccolingual & 492.3 & 21.93 & 454.0 & 532.0 \\
Mesiodistal & 490.1 & 22.29 & 454.0 & 523.0 \\
\hline Middle third & Mean & SD & Minimum & Maximum \\
\hline Buccolingual & 272.6 & 10.64 & 259.0 & 293.0 \\
Mesiodistal & 267.4 & 15.47 & 243.0 & 291.0 \\
\hline
\end{tabular}

Conversely, teeth without the butterfly effect had no critical distinction between buccolingual (492.3 $\mu \mathrm{m})$ and mesiodistal $(490.1 \mu \mathrm{m})$ penetrations (Figure $3 a$ and $b$ and Table 1).

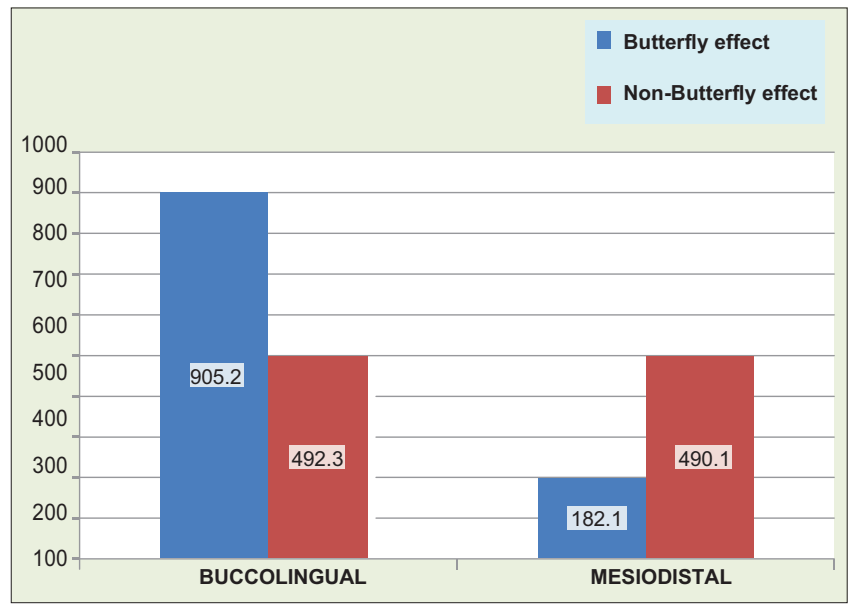

Figure 4: Graphical representation of depth of sealer penetration (in $\mu \mathrm{m}$ ) in root canals of teeth with the butterfly and non-butterfly effect group at the coronal third in buccolingual and mesiodistal direction

Teeth with the butterfly effect had altogether more prominent penetration buccolingually $(905.2 \mu \mathrm{m})$ contrasted with teeth without the impact $(492.3 \mu \mathrm{m}$; $p<0.001)$. On the other side, teeth with the butterfly

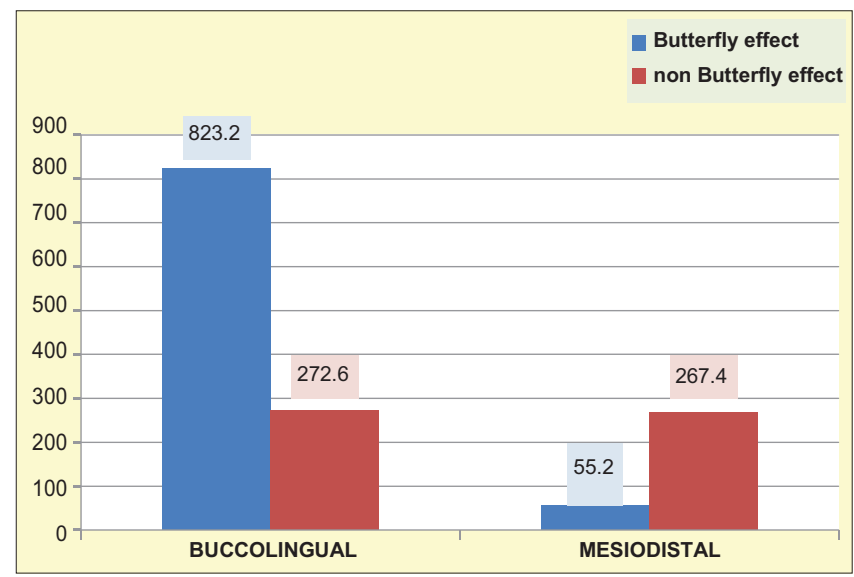

Figure 5: Graphical representation of depth of sealer penetration (in $\mu \mathrm{m}$ ) in root canals of teeth with the butterfly and non-butterfly effect group at the middle third in buccolingual and mesiodistal direction 
Table 2: Comparative statistics of Confocal Laser Scanning Microscopic evaluation of depth of sealer penetration (in $\mu \mathrm{m}$ ) in root canals of teeth with the butterfly (Group 1) and Non-butterfly effect (Group 2 ) at coronal third and middle third respectively

\begin{tabular}{|c|c|c|c|c|}
\hline Coronal third & Butterfly effect $(n=10)$ mean (SD) & Non-butterfly effect $(n=10)$ Mean (SD) & Unpaired t-test & p-value, significance \\
\hline Buccolingual & $905.2(115.94)$ & $492.3(21.93)$ & $\mathrm{t}=11.065$ & $p<0.001^{* *}$ \\
\hline Mesiodistal & $182.1(28.28)$ & $490.1(22.29)$ & $t=-27.04$ & $p<0.001^{* *}$ \\
\hline Middle third & Butterfly effect $(n=10)$ Mean (SD) & Non-butterfly effect ( $n=10)$ Mean (SD) & Unpaired t-test & $\mathrm{p}$-value, significance \\
\hline Buccolingual & $823.2(40.31)$ & $272.6(10.64)$ & $t=41.754$ & $p<0.001^{\star *}$ \\
\hline Mesiodistal & $55.2(7.11)$ & $267.4(15.47)$ & $t=-39.38$ & $P<0.001^{\star *}$ \\
\hline
\end{tabular}

effect had considerably lower mesiodistal penetration $(182.1 \mu \mathrm{m})$ relative to teeth without the effect $(490.1 \mu \mathrm{m}$; $p<0.001$ ) (Table 2).

An average value of $517.4 \mu \mathrm{m}$ of sealer penetration was derived from coronal sections, whereas an average value of $354.6 \mu \mathrm{m}$ of sealer penetration was derived from mid-root sections. Coronal sections had the highest mean penetration relative to the middle sections, and this was a substantial difference $(p<0.001)$ (Figures 4 and 5).

\section{Discussion}

It is generally agreed that the key goal of root canal filling is intended to avoid any interchange between the oral cavity, the root canal system, and the periradicular tissues, to establish a barrier to the infection and reinfection of canals. Sealers are used to create an impermeable seal between the core material and root canal walls. The therapeutic effect of greater penetration of sealers is that it can destroy the bacteria residing in the dentinal tubules and may have an effect on the treatment efficiency. Sealer containing antibacterial active ingredients could be more effective through closer contact with isolated bacteria by infiltration into the dentinal tubules [1]. There are many factors influencing the percentage and maximum depth of sealer penetration. These factors include the effectiveness of the removal of the smear layer, the physical and chemical properties of the sealer, the obturation technique, and the anatomy of the root canal system [13]. The flow of a sealer determines how effectively it obturates accessory canals, irregularities on the dentinal wall, and spaces between the core filling materials [14].

The "butterfly" effect was photographed by Beust in 1931 as an optical phenomenon in some cross-sections of tooth roots [8]. Russell et al. showed that the density of dentinal tubules was significantly higher in the root sections cut mesiodistally and lowest buccolingually that showed significantly deeper penetration in a buccolingual direction compared with teeth without the effect [9]. This study shows that the presence of the butterfly effect has an influence on sealer penetration into dentinal tubules. In a buccolingual direction, teeth with the effect showed consistently significant deeper penetration compared to teeth without the effect. Many species seen within the infected root canal have the propensity to penetrate deeply into the dentinal tubules, such as facultative and anaerobic specie [15]. According to Orstavik, sealers play a key role in sealing the root canal system with entombment of residual microorganisms and filling of inaccessible areas of the prepared canal [4].

In a study conducted by Dalmia et al. [16], Sealapex showed the highest antimicrobial activity against Enterococcus faecalis. Cobankara et al. (2006) and Ishimura et al. (2007) proved that a calcium hydroxide sealer has not only adequate biological but also physical and chemical properties, such as sealability [17], [18]. Estrela et al. proposed that the speed of dissociation into calcium ions and hydroxyl ions affects the antimicrobial mechanism in calcium hydroxide-based sealers. These dissociated hydroxyl ions produce a high $\mathrm{pH}$ environment inhibiting enzymatic activity that is necessary for microbial growth, metabolism, and cell division. Inferior mesiodistal penetration of sealers can have a detrimental effect on the outcome of root canal treatment in teeth with the butterfly effect. Likewise, the presence of the butterfly effect can affect the penetration of intracanal medications such as calcium hydroxide and luting agents used during post-cementation. However, additional studies are needed to assess this.

Von Arx et al. analyzed the varied characteristics of root sections and identified the presence of "frosted dentine," which was more common in premolars and molars than in anterior teeth [19]. The clinical significance of the butterfly effect may be greater in posterior teeth. An investigation shows that the hardness scores were lower buccolingually than mesiodistally in teeth exhibiting the butterfly effect. This could help explain vertical root fractures occurring more frequently in the buccolingual direction [20]. With increasing age, the number of dentinal tubules is recorded to decrease significantly and this may affect sealer penetration [21]. The depth of sealer penetration can be compromised by calcium hydroxide dressings in the root canal because it is not always possible to extract this material completely before obturation [22]. The penetration depths reported in this in vitro study may be higher than clinically expected when treatment with multiple visits is done.

The root canal filling techniques may influence the power of dentinal tubule penetration of the endodontic sealer. Consistent with De-Deus et al. [23] vertical condensation of warm gutta-percha showed a deeper tubule penetration than cold techniques. Some studies with warm vertical compaction techniques have shown consistent gutta-percha and sealer penetration 
into the dentinal tubules [24]. This study records superior penetration of Sealapex in coronal root sections relative to the middle sections. This result is in line with previous researches that have studied several sealers and obturation techniques and has recorded greater coronal mean penetration. While apical root sections have not been included in this analysis, regional differences may be explained by the increasing complexity of the root canal anatomy and the reduced number and patency of dentinal tubules toward the apical portion of the root canal [21]. EDTA is effective in smear layer removal from both coronal and middle thirds. Machine-assisted irrigation equipment and irrigation activation result in improved irrigation in both quantity and efficiency at the apical third stage, thereby allowing the smear layer removal to be more effective. It has been documented that the EndoActivator system allows greater penetration of an irrigant into all areas of endodontic space and effectively cleanses debris from lateral canals, eliminates the smear layer, and dislodges artificial biofilm clumps (Caron, 2007) [25].

The CLSM was used to test the Sealapex penetration ability, as it could provide a thorough description of the nature and distribution of sealer in dentinal tubules while applying fluorescent rhodamine $B$ to it. Another benefit of using CLSM is that the samples can be visualized in different depths. It does not encourage sample dehydration and as compared to SEM, it creates fewer items. Complete obturation of the dentinal tubules was revealed with higher fluorescence while lower fluorescence indicated partial or incomplete obturation [26].

\section{Conclusion}

Within the confinements of this study, it can be inferred that root sections with the butterfly effect have a lower density of tubules mesiodistally, relating to the wings of the butterfly. The presence of the butterfly effect impacts sealer penetration into the dentinal tubules. Roots with the impact show more prominent penetration buccolingually. This may upgrade the burial of microscopic organisms, which could prompt improved treatment results. Coronal sections of roots have unrivaled infiltration in contrast with the middle sections. The sealer penetration in the middle segments was altogether progressively greater in teeth without the butterfly effect.

\section{References}

1. Nikhil V, Singh R. Confocal laser scanning microscopic investigation of ultrasonic, sonic, and rotary sealer placement techniques. J Conserv Dent. 2013;16(4):294$9 . \quad$ https://doi.org/10.4103/0972-0707.114348 PMid:23956528

2. Khandelwal $\mathrm{D}$, Ballal NV. Recent advances in root canal sealers Int J Clin Dent. 2016;9(3):183-94.

3. Hoen MM, LaBounty GL, Keller DL. Ultrasonic endodontic sealer placement. J Endod. 1988;14(4):169$74 . \quad$ https://doi.org/10.1016/s0099-2399(88)80257-7 PMid:3268635

4. Orstavik D. Materials used for root canal obturation: Technical, biological and clinical testing. Endod Topics. 2005;12:25-38. https://doi.org/10.1111/j.1601-1546.2005.00197.x

5. Vitti RP, Prati C, Silva EJ, Sinhoreti MA, Zanchi CH, de Souza e Silva MG, et al. Physical properties of MTAfillapex sealer. JEndod. 2013;39(7):915-18. https://doi.org/10.1016/j.joen.2013.04.015 PMid:23791263

6. Beust TB. Reactions of the dentinal fibril to external irritation. $J$ Am Dent Assoc. 1931;18(6):1060-73.

7. Vasiliadis L, Darling AI, Levers BG. The amount and distribution of sclerotic human root dentine. Arch Oral Biol. 1983;28(7):6459. https://doi.org/10.1016/0003-9969(83)90013-4

8. Russell AA, Chandler NP, Hauman C, Siddiqui AY, Tompkins GR. The butterfly effect: An investigation of sectioned roots. J Endod. 2013;39(2):208-10. https://doi.org/10.1016/j.joen.2012.09.016 PMid:23321232

9. Russell A, Friedlander L, Chandler N. Sealer penetration and adaptation in root canals with the butterfly effect. Aust Endod J. 2018;44(3):225-34. https://doi.org/10.1111/aej.12238 PMid:29034531

10. Russell A. The Butterfly Effect: An Investigation of Sealer Penetration, Adaptation and Apical Crack Formation in Filled Root Canals, Doctoral Dissertation. New Zealand: University of Otago.

11. Desai S, Chandler N. Calcium hydroxide-based root canal sealers: A review. J Endod. 2009;35(4):47580. $\quad$ https://doi.org/10.1016/j.joen.2008.11.026 PMid: 19345790

12. Arikatla SK, Chalasani U, Mandava J, Yelisela RK Interfacial adaptation and penetration depth of bioceramic endodontic sealers. J Conserv Dent. 2018;21(4):373-7. https://doi.org/10.4103/jcd.jcd_64_18 PMid:30122816

13. Nielsen BA, Craig Baumgartner J. Comparison of the EndoVac system to needle irrigation of root canals. J Endod. 2007;33(5):611-5. https://doi.org/10.1016/j.joen.2007.01.020 PMid: 17437884

14. Kuci A, Alacam T, Yavas O, Ergul-Ulger Z, Kayaoglu G. Sealer penetration into dentinal tubules in the presence or absence of smear layer:Aconfocal laser scanning microscopic study. J Endod. 2014;40(10):1627-31. https://doi.org/10.1016/j.joen.2014.03.019 PMid:25260735

15. Love RM, Jenkinson HF. Invasion of dentinal tubules by oral Bacteria. Crit Rev Oral Biol Med. 2002;13:171-83. PMid:12097359

16. Dalmia S, Gaikwad A, Samuel R, Aher G, Gulve M, Kolhe S. Antimicrobial efficacy of different endodontic sealers against Enterococcus faecalis: An in vitro study. J Int Soc Prev Community Dent. 2018;8(2):104-9. https://doi.org/10.4103/jispcd.jispcd 2918 PMid:29780734

17. Cobankara FK, Orucoglu H, Sengun A, Belli S. The quantitative evaluation of apical sealing of four endodontic sealers. J Endod. 2006;32:66-8. https://doi.org/10.1016/j.joen.2005.10.019 PMid:16410073

18. Ishimura $H$, Yoshioka $T$, Suda H. Sealing ability of new adhesive root canalfillingmaterialsmeasuredbynewdyepenetrationmethod.Dent Mater J. 2007;26(2):290-5. https://doi.org/10.4012/dmj.26.290 PMid: 17621947 
19. Von Arx T, Steiner RG, Tay FR. Apical surgery: Endoscopic findings at the resection level of 168 consecutively treated roots. Int Endod J. 2011;44(4):290$302 . \quad$ https://doi.org/10.1111/j.1365-2591.2010.01811.x PMid:21226737

20. Sahu Y, Deshmukh P, Jain A, Sahu A. The butterfly effect: An investigation of hardness and density of sectioned roots. J Oral Dent Health. 2017;1(3):1-4.

21. Carrigan PJ, Morse DR, Furst ML, Sinai IH. A scanning electron microscopic evaluation of human dentinal tubules according to age and location. J Endod. 1984;10(8):35963. $\quad$ https://doi.org/10.1016/s0099-2399(84)80155-7 PMid:6590745

22. MaJ,ShenY,YangY,GaoY,WanP, GanY,etal.Invitrostudyofcalcium hydroxide removal from mandibular molar root canals. J Endod. 2015;41(4):553-8. https://doi.org/10.1016/j.joen.2014.11.023 PMid:25596727

23. De-Deus G, Gurgel-Filho ED, Maniglia-Ferreira C, CoutinhoFilho $\mathrm{T}$. Influence of the filling technique on depth of tubular penetration of root canal sealer: A scanning eletron microscopy study. Braz J Oral Sci. 2016;12:433-8. https://doi. org/10.1111/j.1747-4477.2004.tb00164.x

24. Gutmann JL. Adaptation of injected thermoplasticized gutta-percha in the absence of the dentinal smear layer. Int Endod J. 1993;26(2):87-92. https:// doi.org/10.1111/j.1365-2591.1993.tb00548.x PMid:8330939

25. Kumar VR, Bahuguna N, Manan R. Comparison of efficacy of various root canal irrigation systems in removal of smear layer generated at apical third: An SEM study. J Conserv Dent. 2015;18(3):252-6. https://doi.org/10.4103/0972-0707.157267 PMid:26069415

26. Montero-Miralles $P$, Castillo-Oyague $R$, de la Fuente IS, Lynch CD, Castillo-Dali G, Torres-Lagares D. Effect of the Nd:YAG laser on sealer penetration into root canal surfaces: A confocal microscope analysis. J Dent. 2014;42(6):753-9. https://doi.org/10.1016/j.jdent.2014.03.017 PMid:24721523 